\title{
HUBUNGAN INTENSITAS BERMAIN GAME ONLINE DENGAN KECERDASAN EMOSIONAL PADA MAHASISWA PROGRAM STUDI S1 PENJAS KESREK
}

\author{
Adi Pratama ${ }^{1}$, Rinda Fithriyana ${ }^{2}$, Alini $^{3}$ \\ Program Studi Sarjana Keperawatan, Universitas Pahlawan Tuanku Tambusai \\ Adipratamaa78@gmail.com¹,rindaup@gmail.com²
}

\begin{abstract}
One of the causes of low emotional intelligence is playing online games. Emotional intelligence is the ability to recognize emotions. The intensity of playing online games is the length of time a person spends playing online games. Apart from positive impacts, there are also negative impacts for gamers. The negative effects that play has on individuals are addiction to games, being scolded by parents, lazy, wasteful, speaking harsh and dirty, declining grades, lying to parents, difficulty following lessons, violence against children, and eye damage. The purpose of this study was to determine the relationship between the intensity of playing online games and emotional intelligence in undergraduate students of Physical Education Program at the University of Pahlawan Tuanku Tambusai in 2020. The design of this study was correlative with a cross sectional design with a random sampling method. This research was conducted on May 17-31 in 2020. The population in this study were all male students of the Physical Education Study Program at Pahlawan Tuanku Tambusai University, totaling 139 people with a total sample of 58 people. The measuring instrument used is a questionnaire. The analysis used was univariate and bivariate using the chi-square test. The results showed that there was a relationship between the intensity of playing online games and emotional intelligence in the Undergraduate Program of Physical Education, with a p-value of 0.000 ( $p<0.05)$. It is expected that respondents will reduce the intensity of playing online games in order to have good emotional intelligence.
\end{abstract}

Key words $\quad$ : Emotional Intelligence, Intensity of Playing Online Games, Students

\section{ABSTRAK}

Salah satu penyebab rendahnya kecerdasan emosional adalah bermain game online. Kecerdasan emosional adalah kemampuan untuk mengenali emosi. Intensitas bemain game online adalah lamanya waktu yang digunakan seseorang dalam bermain game online. Selain dampak positif, terdapat juga dampak negatif bagi para gamers. Dampak negatif yang diberikan dari permainan bagi inidividu adalah kecanduan permainan, dimarahi oleh orang tua, malas, boros, berkata kasar dan kotor, nilai merosot, berbohong kepada orang tua, sulit mengikuti pelajaran, timbulnya kekerasan pada anak, dan merusak mata. Tujuan dari penelitian adalah untuk mengetahui hubungan intensitas bermain game online dengan kecerdasan emosional pada mahasiswa Prodi S1 Penjas Kesrek di Universitas Pahlawan Tuanku Tambusai tahun 2020. Desain penelitian ini adalah korelatif dengan rancangan cross sectional dengan metode pengambilan sampel random sampling. Penelitian ini dilaksanakan pada tanggal 17-31 mei tahun 2020. Populasi pada penelitian ini adalah seluruh mahasiswa laki-laki Prodi Penjas Kesrek di Universitas Pahlawan Tuanku Tambusai yang berjumlah 139 orang dengan jumlah sampel sebanyak 58 orang. Alat ukur yang digunakan adalah kuesioner. Analisa yang digunakan adalah univariat dan bivariat menggunakan uji chi-square. Hasil penelitian menunjukkan adanya hubungan intensitas bermain game online dengan kecerdasan emosional pada mahasiswa Prodi S1 Penjas Kesrek dengan p-value 0,000 ( $<<0,05)$. Diharapkan kepada responden untuk mengurangi intensitas bermain game online agar memiliki kecerdasan emosional yang baik.

Kata Kunci $\quad$ : Intensitas Bermain Game Online, Kecerdasan Emosional, Mahasiswa 


\section{PENDAHULUAN}

Era globalisasi saat ini, segala hal yang dilakukakan manusia tidak pernah lepas dari emosi, karena dengan adanya emosi manusia dapat menunjukkan keberadaannya dalam menangani masalah pribadi maupun sosial. Esensi pentingnya kecerdasan emosi bagi remaja menurut Meyer (2004) dalam Apriliyani (2020) terdapat beberapa keuntungan, yang pertama menjadi alat untuk membantu pengendalian diri, sehingga tidak terjerumus kedalam tindakan yang dapat merugikan diri sendiri maupun orang lain. Kedua, kecerdasan emosi bisa diimplementasikan sebagai cara yang sangat baik untuk memasarkan atau membesarkan ide/gagasan.

Menurut Goleman (2009) dalam Haryanto (2019) menjelaskan kecerdasan emosi merupakan kemampuan emosi yang meliputi kemampuan untuk mengendalikan diri, memiliki daya tahan ketika menghadapi suatu masalah, mampu mengendalikan impuls, memotivasi diri, mampu mengatur suasana hati, kemampuan berempati dan membina hubungan dengan orang lain.

Kecerdasan emosional tidak berarti kesempurnaan dalam relasi manusia, namun diperlukan untuk meningkatkan keterampilan sosial. Keterampilan sosial yang bagus membantu menciptakan interaksi yang lebih baik. Dalam berelasi, kecerdasan emosinal diperlukan karena kecerdasan emosional adalah kemampuan khusus untuk membaca perasaan terdalam mereka yang melakukan kontak, dan menangani secara efektif. Sementara pada saat yang sama dapat memotivasi diri sendiri, dan memenuhi tantangan manajemen relasi Menurut Meyer dalam Shalihat (2013).

Menurut Kholidiyah (2013) rendahnya kecerdasan emosi pada remaja terungkap pada fenomena semakin bertambahnya jumlah remaja yang terlibat dalam penyalahgunaan obat bius, kriminalitas, kekerasan, bertambahnya remaja yang depresi, kejadian kehamilan tak diinginkan, kenakalan dan putus sekolah.

Fakta yang terjadi di lapangan menurut Haryanto (2019), masih menunjukkan rendahnya kecerdasan emosi pada mahasiswa. Salah satu contoh 3 mahasiswa Universitas Muslim Indonesia di Makassar terlibat kasus penganiayaan pada saat ospek yang menyebabkan kematian mahasiswi kedokteran. Selanjutnya mahasiswa Universitas Sebelas Maret di Solo yang melakukan tindakan bunuh diri karena depresi dengan loncat dari lantai empat gedung kampus, bahkan mahasiswa tersebut sempat melakukan perusakan terhadap sejumlah mobil di salah satu perbelanjaan di Solo Baru. Hal tersebut menunjukkan kecenderungan rendahnya kecerdasan emosional pada mahasiswa.

Salah satu faktor yang berpengaruh terhadap kecerdasan emosi yaitu bermain game online. Mahasiswa memiliki kecenderungan untuk mengikuti trend dan mudah terpengaruh oleh lingkungan. Ditambah dengan kemudahan mengakses game online yang memiliki fasilitas menarik akan membuat remaja semakin tertarik bermain game online (Haryanto, 2019).

Permainan dengan menggunakan koneksi internet dikenal sebagai permainan online. Permainan online menjadi salah satu hal yang banyak dimainkan oleh remaja di Indonesia. Dengan adanya permainan online maka setiap pemain dapat bermain dengan pemain lain secara langsung dan terhubung. Inilah yang menjadi salah satu daya tarik dari permainan online, setiap user dapat berinteraksi dan bermain satu dengan yang lainnya melalui permainan yang dimainkan (Apriliyani, 2020).

Menurut Harsono (2014) dampak bermain permainan bagi individu antara lain permainan sebagai sarana belajar, permainan membuat anak pandai berbahasa Inggris, menumbuhkan sikap pantang menyerah, memudahkan dalam penyelesaian masalah, menumbuhkan rasa ingin tahu, menambah wawasan, belajar berimajinasi, lebih ambisius, mendapatkan uang dari 
permaian. Selain dampak positif, terdapat juga dampak negatif bagi para gamers. Dampak negatif yang diberikan dari permainan bagi inidividu adalah kecanduan permainan, dimarahi oleh orang tua, malas, boros, berkata kasar dan kotor, nilai merosot, berbohong kepada orang tua, sulit mengikuti pelajaran, timbulnya kekerasan pada anak, dan merusak mata.

Hasil penelitian oleh Immanuel dalam Haryanto (2019) menunjukan bahwa pemain game online kehilangan relasi, kehilangan pekerjaan, kesempatan karir, dan kesempatan pendidikan, serta menjadikan game online sebagai cara untuk melarikan diri dari masalah.

Remaja merupakan masa transisi dari periode anak menuju dewasa. Remaja yang dalam bahasa aslinya disebut adolescence, berasal dari bahasa Latin adolescence yang artinya "tumbuh atau tumbuh untuk mencapai kematangan". Masa remaja merupakan salah satu tahapan perkembangan manusia yang dianggap sangat penting karena perubahanperubahan yang dialami masa remaja akan memberikan dampak langsung pada individu yang bersangkutan dan akan mempengaruhi perkembangan selanjutnya (Sarwono, 2012).

Dari hasil studi pendahuluan yang dilakukan peneliti pada tanggal 25 Maret 2020 terhadap 30 orang mahasiswa dari 3 Prodi di Universitas Pahlawan Tuanku Tambusai Riau. 10 orang dari Prodi S1 Penjas Kesrek didapatkan 8 orang bermain game online dan 2 tidak bermain game online, 10 orang dari Prodi Keperawatan didapatkan 3 orang bermain game online dan 7 orang tidak bermain game online, 10 orang dari Prodi Hukum didapatkan 6 orang bermain game online dan 4 orang tidak bermain game online.

Pada saat studi pendahuluan yang aktif bermain game ialah berjenis kelamin laki-laki. Peneliti melakukan studi pendahuluan dengan metode wawancara menunjukkan bahwa mahasiswa memiliki permasalahan kecerdasan emosi, hal ini bisa dilihat dari mahasiswa yang mengaku kurang fokus pada perkuliahan, sering membolos kuliah untuk bermain game online, jarang mengerjakan tugas kuliah dan kurang pandai mengatur waktu. Selain itu juga didapatkan bahwa sebagian mahasiswa mengaku menjadi tidak peduli pada lingkungannya baik dalam lingkungan keluarga maupun masyarakat. Ketidakpedulian ini dapat menumpulkan kemampuan dalam empati, mengekspresikan emosi dengan tepat, mengelola emosi, dan semua itu merupakan aspek dari kecerdasan emosi.

Berdasarkan wawancara yang dilakukan tersebut, menujukkan bahwa masih rendahnya kecerdasan emosional pada mahasiswa yang aktif sebagai pemain game online. Dari data yang di dapat, Prodi S1 Penjas Kesrek memiliki jumlah mahasiswa laki-laki 139 orang, Prodi S1 Keperawatan memiliki jumlah mahasiswa lakilaki 114 orang, kemudian Prodi S1 Hukum memiliki jumlah mahasiswa laki-laki 85 orang. Prodi S1 Penjas Kesrek memiliki jumlah mahasiswa laki-laki paling banyak diantara prodi yang lainnya.

Berdasarkan uraian diatas, peneliti tertarik untuk melakukan penelitian bagaimana hubungan intensitas bermain game online dengan kecerdasan emosional pada mahasiswa Prodi S1 Penjas kesrek.

Adapun tujuan dari penelitian ini adalah untuk menganalisis hubungan antara intensitas bermain game online dengan kecerdasan emosional mahasiswa Prodi S1 Penjas Kesrek.

\section{METODE}

Jenis penelitian ini menggunakan desain korelatif, dengan pendekatan cross sectional Penelitian dilaksanakan di Universitas Pahlawan Tuanku Tambusai pada tanggal 17-31 Mei 2020. Populasi seluruh mahasiswa laki-laki Prodi S1 Pendidikan Jasmani Kesehatan dan Rekreasi yang berjumlah 139 orang. Sampel yaitu sebagian mahasiswa laki-laki prodi S1 
Pendidikan Jasmani Kesehatan dan Rekreasi Universitas Pahlawan Tuanku Tambusai Riau.

Teknik pengambilan sampel pada penelitian ini merupakan teknik simple random Sampling, dimana pengambilan sampel dilakukan secara acak (Notoatmodjo, 2012). Sampel pada penelitian ini sebanyak 58 orang. Jumlah Sampel dihitung dengan menggunakan rumus dari Slovin untuk tingkat kesalahan 10\% (Notoatmodjo, 2012).

Dalam penelitian ini, peneliti menggunakan kuesioner untuk mengukur variabel independen dan variabel dependen. Kuesioner di berikan kepada responden menggunakan sistem online. Peneliti memodifikasi skala baku agar sesuai dengan tujuan dari peneliti ini. Analisa yang digunakan adalah analisa univariat dan analisa bivariat. Analisis bivariat menggunakan uji chi-square dengan tingkat kepercayaan $95 \%$ dan tingkat kemaknaan $\mathrm{p}$ value <0,05. Analisa data menggunakan bantuan program komputerisasi.

\section{HASIL}

\section{Karakteristik Responden}

Karakteristik responden terdiri dari usia dan semester. Distribusi frekuensi dapat dilihat pada tabel 1 dan 2 berikut ini :

Tabel 1 :Distribusi Frekuensi Karakteristik Responden Berdasarkan Usia Pada Mahasiswa Prodi S1 Penjas Kesrek.

\begin{tabular}{cccc}
\hline No & $\begin{array}{c}\text { Usia } \\
\text { (Tahun) }\end{array}$ & Frekuensi & Presentase \\
\hline 1 & 17 & 1 & 1,7 \\
2 & 18 & 3 & 5,2 \\
$\mathbf{3}$ & $\mathbf{1 9}$ & $\mathbf{1 5}$ & $\mathbf{2 5 , 9}$ \\
4 & 20 & 14 & 24,1 \\
$\mathbf{5}$ & $\mathbf{2 1}$ & $\mathbf{1 5}$ & $\mathbf{2 5 , 9}$ \\
6 & 22 & 6 & 10,3 \\
7 & 23 & 1 & 1,7 \\
8 & 24 & 2 & 3,4 \\
9 & 28 & 1 & 1,7 \\
\hline & Jumlah & $\mathbf{5 8}$ & $\mathbf{1 0 0}$ \\
\hline
\end{tabular}

Dari tabel 1 dapat dilihat bahwa dari 58 mahasiswa Prodi Penjas Kesrek terbanyak usia 19 dan 21 tahun sebanyak 15 orang $(25,9 \%)$.

Tabel 2 :Distribusi Frekuensi Karakteristik Responden Berdasarkan Semester Pada Mahasiswa Prodi S1 Penjas Kesrek.

\begin{tabular}{cccc}
\hline No & Semester & Frekuensi & $\begin{array}{c}\text { Persentase } \\
(\mathbf{\%})\end{array}$ \\
\hline $\mathbf{1}$ & $\mathbf{2}$ & $\mathbf{2 2}$ & $\mathbf{3 7 , 9}$ \\
2 & 4 & 19 & 32,8 \\
3 & 6 & 17 & 29,3 \\
\hline & Jumlah & $\mathbf{5 8}$ & $\mathbf{1 0 0}$ \\
\hline
\end{tabular}

Dari tabel 2 dapat dilihat dari 58 mahasiswa Prodi Penjas Kesrek terbanyak yaitu semester 2 dengan jumlah 22 orang $(37,9 \%)$.

\section{Analisa Univariat}

Analisa univariat menggambarkan distribusi frekuensi responden berdasarkan. intensitas bermain game online dan kecerdasan emosional. Untuk lebih jelasnya dapat dilihat pada tabel berikut ini:

Tabel 3 :Distribusi Frekuensi Intensitas Bermain Game Online Pada Mahasiswa Prodi S1 Penjas Kesrek.

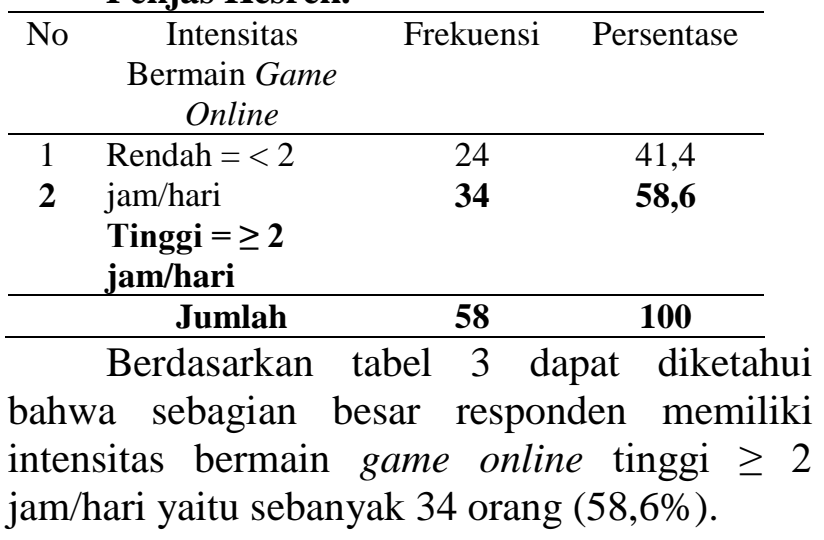


Tabel 4 :Distribusi Frekuensi Kecerdasan Emosional Pada Mahasiswa Prodi S1 Penjas Kesrek.

\begin{tabular}{llcc}
\hline No & Kecerdasan Emosional & Frekuensi & $\begin{array}{c}\text { Persentase } \\
(\%)\end{array}$ \\
\hline $1 \quad$ Baik & 28 & 48,3 \\
$\mathbf{2}$ & Kurang Baik & $\mathbf{3 0}$ & $\mathbf{5 1 , 7}$ \\
\hline \multicolumn{2}{c}{ Jumlah } & $\mathbf{5 8}$ & $\mathbf{1 0 0}$ \\
\hline \multicolumn{2}{c}{ Berdasarkan tabel } & 4 dapat & diketahui \\
bahwa sebagian besar responden memiliki & men \\
kecerdasan emosional kurang baik yaitu \\
sebanyak 30 orang (51,7\%).
\end{tabular}

\section{Analisa Bivariat}

Analisa bivariat ini menggambarkan hubungan intensitas bermain game online dengan kecerdasan emosional pada mahasiswa prodi S1 Penjas Kesrek. Hasil analisis disajikan pada tabel 5 berikut ini:

Tabel 5 :Hubungan Intensitas Bermain Game Online Dengan Kecerdasan Emosional Pada Mahasiswa Prodi S1 Penjas Kesrek.

\begin{tabular}{|c|c|c|c|c|c|c|c|c|c|}
\hline \multirow{3}{*}{ NO } & \multirow{3}{*}{$\begin{array}{l}\text { Intensitas } \\
\text { Bemain } \\
\text { Game } \\
\text { Online }\end{array}$} & \multicolumn{4}{|c|}{ Kecerdasan Emosional } & \multirow{2}{*}{\multicolumn{2}{|c|}{ Total }} & \multirow{3}{*}{$\begin{array}{c}\mathrm{P} \\
\text { value }\end{array}$} & \multirow{3}{*}{ OR } \\
\hline & & \multicolumn{2}{|c|}{ Baik } & \multicolumn{2}{|c|}{ Kurang Bak } & & & & \\
\hline & & $\mathrm{N}$ & $\%$ & $\mathrm{~N}$ & $\%$ & $\mathrm{~N}$ & $\%$ & & \\
\hline 1 & Tingg & 7 & 20,6 & 27 & 79,4 & 34 & 100 & & \\
\hline 2 & Rendah & 21 & 87,5 & 3 & 12,5 & 24 & 100 & 0,000 & 0.037 \\
\hline & Total & 28 & 48,3 & 30 & 51,7 & 58 & 100 & & \\
\hline
\end{tabular}

Berdasarkan tabel 5 dapat dilihat bahwa dari 34 orang yang memiliki intensitas bermain game online tinggi ( $\geq 2 \mathrm{jam} / \mathrm{hari})$, terdapat 7 orang $(20,6 \%)$ yang memiliki kecerdasan emosional baik, sedangkan dari 24 orang yang memiliki intensitas bermain game online rendah ( $<2 \mathrm{jam} / \mathrm{hari})$, terdapat 3 orang $(12,5 \%)$ yang memiliki kecerdasan emosional kurang baik. Berdasarkan uji statistik diperoleh nilai $\mathrm{p}$ value $=0,000(p<0,05)$, dengan derajat kemaknaan $(\alpha$ $=0,05)$. Ini berarti terdapat hubungan yang signifikan antara intensitas bermain game online dengan kecerdasan emosional pada mahasiswa prodi S1 Penjas Kesrek. Dari hasil penelitian diketahui nilai $\mathrm{OR}=0,037$, hal ini berarti mahasiswa yang intensitas bermain game online tinggi ( $\geq 2$ jam/hari) berpeluang 0,037 kali untuk memiliki kecerdasan emosional kurang baik.

\section{PEMBAHASAN}

Berdasarkan hasil penelitian, diketahui bahwa ada hubungan antara intensitas bermain game online dengan kecerdasan emosional pada mahasiswa Prodi S1 Penjas Kesrek di Universitas Pahlawan Tuanku Tambusai (pvalue $=0,000 \leq 0,05)$. Dari 35 mahasiswa orang yang memiliki intensitas bermain game online tinggi ( $\geq 2$ jam/hari), terdapat 7 orang (20,0\%) yang memiliki kecerdasan emosional baik, sedangkan dari 23 orang yang memiliki intensitas bermain game online rendah $(<2$ jam/hari), terdapat 2 orang $(8,7 \%)$ yang memiliki kecerdasan emosional kurang baik.

Hasil analisis adanya hubungan yang signifikan antara intensitas bermain game online dengan kecerdasan emosional menunjukkan bahwa semakin tinggi intensitas bermain game online maka akan semakin rendah kecerdasan emosionalnya, begitu juga sebaliknya bila semakin rendah intensitas bermain game online maka akan semakin tinggi kecerdasan emosionalnya.

Menurut asumsi peneliti banyaknya mahasiswa yang memiliki intensitas bermain game online tinggi ( $\geq 2$ jam/hari) disebabkan karena faktor lingkungan dan pengaruh dari teman sebaya. Dari hasil analisa ada 7 mahasiswa yang memiliki intensitas bermain game online tinggi $(\geq 2 \mathrm{jam} / \mathrm{hari})$ tetapi memiliki kecerdasan emosional baik disebabkan karena mahasiswa dapat memahami secara lebih efektif terhadap kepekaan emosi yang mencakup kemampuan memotivasi diri sendiri dan orang lain, mampu mengendalikan emosi, dan mempunyai kekuatan berfikir yang positif dan optimis. Dari hasil analisa ada 2 mahasiswa yang memiliki intensitas bermain game online rendah $(<2 \mathrm{jam} / \mathrm{hari})$ tetapi memiliki kecerdasan emosional kurang baik 
disebabkan karena tidak tenang dalam menghadapi masalah, tidak bisa bekerja sama dengan orang lain, dan enggan memulai percakapan dengan orang yang belum dikenal.

Hasil penelitian ini juga sejalan dengan penelitian yang dilakukan pratiwi, dkk (2012) terhadap 76 remaja yang berusia 13 hingga 18 tahun (masih duduk di bangku SMP sampai dengan SMA) dan mengalami kecanduan game online. Dari hasil penelitian tersebut diketahui bahwa tedapat hubungan negatif antara efikasi diri akademik dan keterampilan sosial dengan perilaku adiksi game online.

Pada penelitian Dewi (2014) mengatakan bahwa terdapatnya hubungan negatif antara intensitas bermain game online dengan interaksi sosial. Semakin tinggi intensitas bermain game online, maka semakin rendah interaksi sosialnya. Hasil penelitian didukung oleh penelitian yang dilakukan oleh Steinkuehler (2006) dalam Kholidiyah (2013) pengguna media game telah menyebabkan penurunan dalam keterlibatan sipil dan sosial karena media game juga sebagai pengganti keterlibatan langsung dalam dunia sosial kontemporer. Permainan online membantu dalam interaksi secara online dan membantu menyediakan dunia baru dan ide-ide. Namun, manfaat sosial yang diperoleh setidaknya hanya dalam jangka pendek, karena game online lebih khas untuk orang-orang yang pemalu, fanatik, ingin selalu terlihat menonjol, dan mendapat perhatian yang memilih untuk mengisolasi diri dari orang lain.

Penelitian ini didukung oleh penelitian sebelumnya yang dilakukan oleh Laily (2014) mengemukakan hasil analisis terdapat hubungan positif antara bermain permainan online dengan motivasi belajar. Karena terlalu sering bermain permainan online menunjukkan semakin rendah motivasi belajar, sebaliknya semakin rendah bermain permainan online maka semakin tinggi pula motivasi belajar siswa.

Hasil penelitian yang dilakukan oleh Nuhan (2016) menunjukkan bahwa permainan online membuat prestasi belajar menurun. Siswa yang kecanduan permainan online memiliki penyesuaian sosial yang tidak baik karena dalam permainan online sering terjadi konflik dengan teman bermain dalam game tersebut. Sedangkan kondisi psikologis siswa yang mengalami kecanduan permainan online memiliki kondisi emosi yang cenderung pemarah.

Hal di atas diperkuat oleh penelitian yang dilakukan oleh Brian (2005) dalam Apriliyani (2020) anak yang kecanduan permainan online memiliki kondisi psikologis yang berpengaruh terhadap mental seperti banyaknya adegan pada permainan online yang menampilkan tindakan kriminal dan kekerasan seperti perkelahian, pengerusakan, pemerkosaan, pembunuhan, dan lain sebagainya yang secara tidak langsung akan mempengaruhi alam bawah sadar seseorang bahwa kehidupan nyata sama seperti di dalam permainan tersebut. Ciri-ciri seseorang yang mengalami gangguan mental akibat pengaruh permainan online adalah emosional, mudah marah, mudah mengucapkan kata kotor, memaki, mencuri, dan menghambat proses pendewasaan diri.

Agar terciptanya kecerdasan emosi yang baik maka penting untuk memberikan pemahaman yang benar tentang pemanfaatan teknologi khususnya game online sebagai sarana hiburan. Meningkat dan meratanya kecerdasan emosi akan memudahkan subjek dalam mengenali dan memahami dirinya sediri dan orang lain, lebih berempati serta lebih pintar dalam membina hubungan dengan orang lain. Peningkatan kecerdasan emosi dapat dilakukan dengan peningkatan rasa percaya diri, serius dalam menjalin komunikasi, mengembangkan minat juga mengembangkan aset fisik dan psikologis. Semakin baik pendidikan emosi yang diterima remaja maka akan baik pula kecerdasan emosinya (Kholidiyah,2013). 


\section{KESIMPULAN}

Berdasarkan hasil penelitian dapat disimpulkan bahwa terdapat hubungan yang signifikan antara intensitas bermain game online dengan kecerdasan emosional pada mahasiswa Prodi S1 Penjas Kesrek di Universitas Pahlawan Tuanku Tambusai Tahun 2020.

\section{DAFTAR PUSTAKA}

Apriliyani , A. (2020). Hubungan intensitas bermain permainan online dengan kecerdasan emosional (pada remaja pemain mobile legend di kota Samarinda). Ejournal. Psikoborneo, $8(1): 67-82$.

Dewi, N. P. (2014). Hubungan Antara Intensitas Bermain Game Online Dengan Interaksi Sosial Pada Remaja. Jurnal Psikologi. Diunduh dari: http://eprints.ums.ac.id/123456789/3563

Harsono, M. (2014) Pengaruh Bermain Game Terhadap Perkembangan Remaja. Serpong : Surya University Press.

Haryanto, Yuda. (2019). Hubungan antara Intensitas Bermain Game Online Dengan Kecerdasan Emosi Pada Mahasiswa Di Yogyakarta. Skripsi thesis, Universitas Mercu Buana Yogyakarta.

Kolidiyah. U. (2013). Hubugan antara intensitas bermain game online dengan kecerdasan emosi. Journal Indigenous. 2(1), 28-41

Laily, F. L. (2013). Hubungan Antara kecanduan Game Online Dengan Motivasi Belajar Pada Siswa Laki-Laki Kelas Vll SMPN 13 Malang. Jurnal Psikoislammika. 2(1), 110-116.

Notoatmodjo, S. (2012). Metodologi Penelitian Kesehatan. Jakarta: Rineka Cipta.

Nuhan, Y. G. H. (2016). Hubungan Intensitas Bermain Game Online Dengan Prestasi Siswa kelas IV Sekolah Dasar Negeri Jarakan Kabupaten Bantul Yogyakarta. Jurnal pendidikan Guru Sekolah Dasar Edisi 6.

Pratiwi. P. C., Andayani, T. R., \& Karyanta, N. A. (2012). Perilaku Adiksi Game-Online Ditinjau dari Efekasi Diri Akademik dan Keterampilan Sosial pada Remaja di Surakarta. Surakarta: Universitas Sebelas Maret Surakarta

Sadiyah, Munlifatun. (2014). Hubungan Kecerdasan Emosional Dengan Hasil Belajar Mahasiswa Prodi Pendidikan Biologi UNiversitas Negeri Semarang. Skripsi. Universitas Negeri Semarang.

Shalihat, N. A. (2013). Hubungan Antara Kecerdasan Emosional Dan Kecanduan Game Online Pada Mahasiswa Pemain Game Online Di Kota Bandung. Skripsi. Universitas Pendidikan Indonesia.

Suprapto, H. (2017). Metodologi Penelitian untuk Karya Ilmiah. Yogyakarta: Gosyen Publishing 